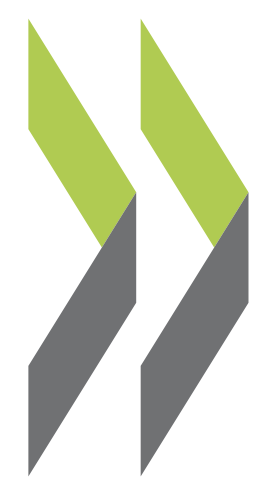

PEB Exchange, Programme on Educational Building 2008/11

Henno Theisens,

OECD Work on Future

Educational Environments
Francisco Benavides,

Hanna Dumont

https://dx.doi.org/10.1787/235174702321 


\section{OECD Work on Future Educational Environments}

Designing school buildings to respond to change is not a new idea. But perhaps what is different today is the kind and degree of change which we have to anticipate. The OECD is carrying out projects that can help in the planning and design of future educational facilities - exploring trends in education and studying innovative learning environments.

Education planners have long grappled with the type of change connected with demography, for example changing local patterns in the number of school places needed over a period of time. But new challenges lie in the complexity and uncertainty which are characteristic of the $21^{\text {st }}$ century world.

The findings of the OECD's project "Schooling for Tomorrow: Trends Shaping Education" show some sources of this uncertainty, including falling birth rates, increasing economic globalisation and growing numbers of single parent families. Such issues suggest that policy makers and education providers alike need to address questions about what education is and how it should be delivered.

Another OECD project, a study of innovative learning environments, is looking at how schools can respond to changes in the type of teaching and learning that make individuals lifelong learners. Developing individuals as self-directed learners, who are able to acquire expert knowledge in different fields and to change careers, benefits the economy and society generally.

Research into learning shows both the importance of allowing students to take control of their own learning and that learning must be a social, cultural, intrapersonal and an active process. Research also demonstrates that an understanding of complex subjects can be best achieved in settings where the learner is engaged with others in the community, in activities where knowledge is being applied.

The learning environments that support this must be fundamentally different from what has gone before, with less emphasis on teachers addressing a group of students in a traditional classroom setting. However, just how the physical environment must respond is a complicated issue. To meet the needs of $21^{\text {st }}$ century learning, the physical environment will have to be agile so that it is capable of providing a mixed range of learning settings from large group spaces to smaller, more individual tutorial type spaces. However, the interaction between a building's users and the physical infrastructure is complex. The physical environment is always a constraint, but a key question might be to what extent does it offer the teachers the freedom and empowerment to do with it what they want. The different learning settings may be facilitated by clever use of furniture which can be easily rearranged in a variety of ways thus providing a range of spaces within spaces. These are all issues that future work of the Programme on Educational Building will explore further, building on the current OECD work on innovative learning environments. 


\section{Schooling for Tomorrow: Trends Shaping Education}

\section{By Henno Theisens, OECD}

While education is about long-term investment in people and society, its decision making tends to be predominantly short-term; this paradox is at the core of the "Schooling for Tomorrow" project being carried out by the OECD Centre for Educational Research and Innovation (CERI). The CERI project has set out to develop frameworks and tools to be useful for people in different situations in many countries for thinking about alternative futures for education. As part of this mission a recent publication - Trends Shaping Education - explores the trends that will shape education in the future.

Today's world is increasingly complex and uncertain, with a growing number of stakeholders making new demands on education. Yet much of education is still determined by short-term thinking preoccupation with pressing immediate problems or simply seeking more efficient ways of maintaining established practice. Neglect of the long term is increasingly problematic in meeting the challenges of complexity and change. People working in education at all levels thus need to be able to look beyond the immediate constraints. Longer-term perspectives in policy and practice are the exception rather than the rule. We lack even the tools and terminology to develop such perspectives.

\section{TRENDS SHAPING EDUCATION}

This publication is designed to inform thinking about major developments that are affecting the future of education and setting challenges for schools. It contains 26 major trends each illustrated by two graphs and followed by three pertinent questions for education. The trends cover a number of key areas: First, there are major demographic trends; these concern OECD countries and lead on to global developments related not to only population levels and movements but also to living conditions and the environment. Second, there are economic trends relating both to the nature of economies and to the kinds of work people do. Third, there are themes related to the digital (and learning) society in which we live, in which education makes its own important contribution are presented. Fourth, there are the political and social factors to do with the role of the state, the social environment and families, and trends concerning sustainability. As well as relevance for education, the criterion for selection has been the presence of international time-proven evidence. The focus is primarily on OECD countries, though where they are available broader global data are used.

\section{Birth rates falling}

It would be impossible to reflect in this short article on the width and depth of Trends Shaping Education, but as an illustration we will focus on two trends and their possible impact on education. The first trend is demographic and focuses on the rapid changes in the number of children being born in OECD countries, with births falling dramatically. Families are smaller, women tend to be older when they have children and an increasing number do not have children at all. Education is part of the story, with higher levels of education tending to be associated with fewer children. The number of children born in OECD countries is now so low that the long-term prospect is population decline, despite the fact that we are living longer. On average, 2.1 children per woman should be born in a country for there to be long-term 
population stability: when it is significantly lower than this, the population drops. By the beginning of the $21^{\text {st }}$ century, only two OECD countries - Mexico and Turkey - were still above the 2.1 line. This is in sharp contrast with many developing countries where fertility levels remain high.

Figure 1 shows just how significant the drop in birth rates has been. In 1960, the OECD average was over 3 births per woman aged 15-49; this number was cut in half in only 43 years. The fall in the number of children being born has been truly dramatic in some countries, such as Korea which has gone from having one of the highest fertility rates of the 30 countries to having one of the lowest.

Figure 1 Birth rates halved since the $1960 \mathrm{~s}$

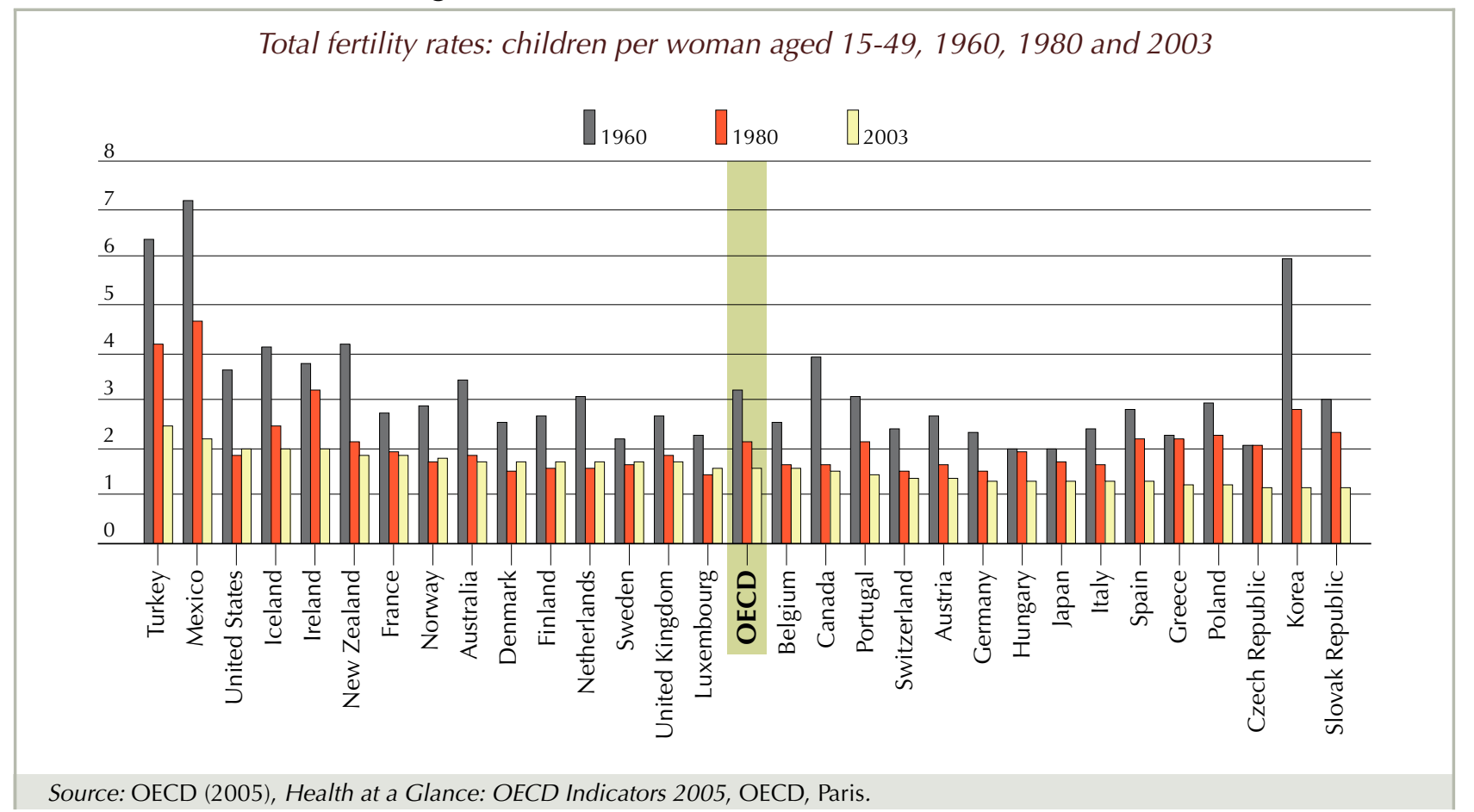

What does this mean for education?

- School rolls fall as numbers of young people fall. For countries or regions that have been experiencing severe teacher shortages this may be a welcome trend. But others face difficult questions regarding how to deal with emptying and closing schools, and the possible reduction in school choices in certain communities.

- Falling enrolments present opportunities, not just problems. Is the opportunity being seized to make resources go further for each student and to engage in innovation that would be impossible if schools were completely full? What about new school designs and buildings?

\section{Computers becoming faster}

The second example from Trends Shaping Education focuses on information technology, which has developed rapidly over the past 40 years, with computers becoming smaller, faster, cheaper and more powerful. Information technology is now an integral part of our daily lives and embedded in many products. Many of us are now living in technological environments and need to adjust to the pace at which these environments are changing. How easily we can access large quantities of information quickly and in different settings is clearly a key matter for education. 
Figure 2 Computers rapidly becoming faster and more powerful

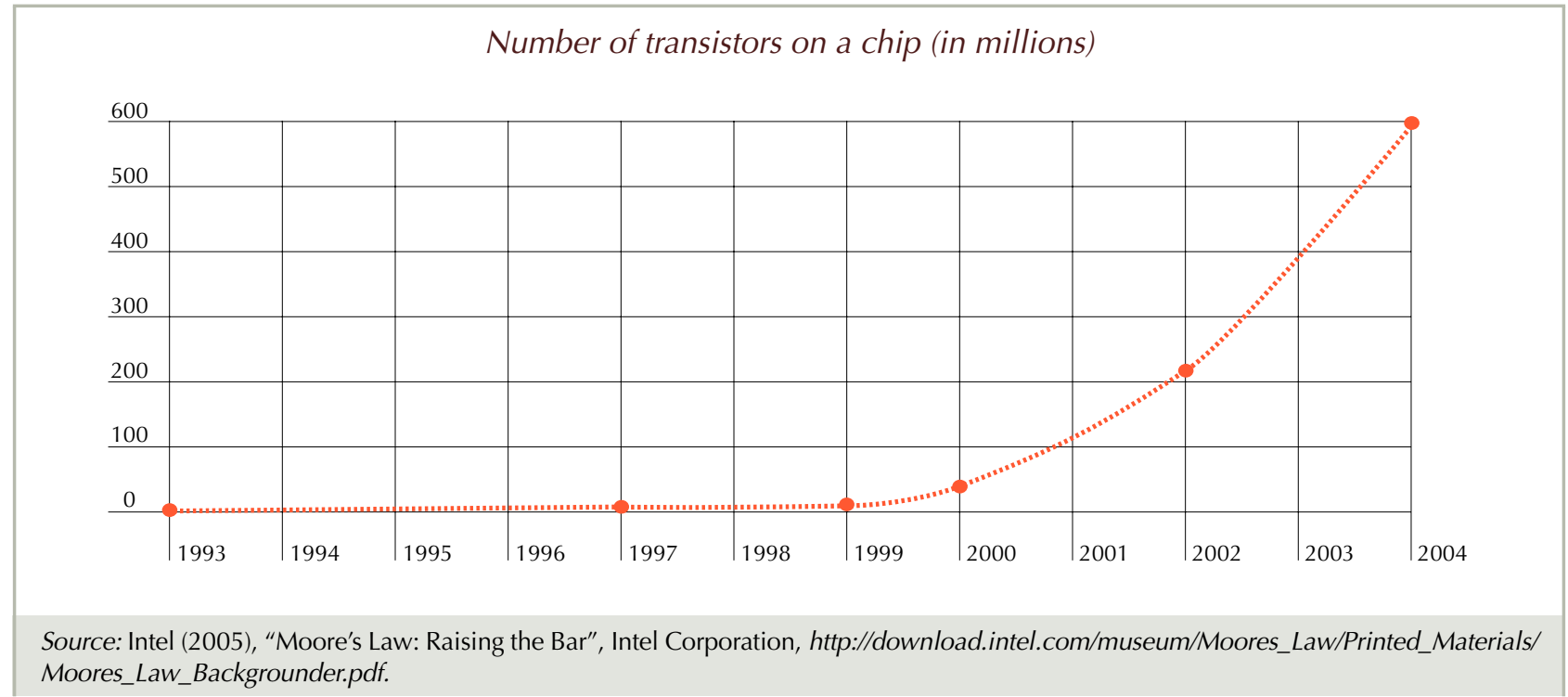

Figure 2 shows the number of transistors put on the chip of a computer's central processing unit - an indication of the computer's speed and power. This has been growing exponentially, along with memory disk capacity, while prices to be paid for computing power and memory have been plummeting. Computers have transformed the way we work and relax, how businesses operate, the conduct of scientific research and the ways governments govern. They are being integrated into other technologies in cars, phones and many other things that used to be "low-tech". There is every reason to suppose that the pace of technological change will continue, though we cannot say precisely in which forms and directions. The consequences for education are uncertain:

- How well have schools kept pace with technological developments, and should they do so? How can we improve teachers' technical knowledge and skills? How well adapted to learning is the information and communications technology (ICT) equipment in schools?

- Does ICT allow for more self-paced, interactive and self-improving styles of learning? How far does and should its potential to personalise learning be exploited, whether in schools or in other places where learning can take place?

\section{BY WAY OF CONCLUSION}

These are only two examples of the wide variety of trends in the publication and the kinds of questions that are raised in response to those trends. CERI hopes this book will help those who are interested in thinking about or discussing the longer-term future of education at international, national or local levels.

Trends Shaping Education is available through the OECD online bookshop: www.oecdbookshop.org.

For more information, contact:

Henno Theisens

OECD Centre for Educational Research and Innovation

2, rue André-Pascal

75775 Paris Cedex 16, France

E-mail: henno.theisens@oecd.org 


\section{Innovative Learning Environments}

By Francisco Benavides, OECD, and Hanna Dumont, Consultant

How can education help individuals achieve their fullest potential? How can today's schools be transformed into the type of teaching and learning environments that make individuals lifelong learners and prepare them for the $21^{\text {st }}$ century? The OECD Centre for Educational Research and Innovation has undertaken a project to address these questions.

In recent decades, OECD economies have experienced a rapid transformation from industrial to knowledge-based systems in which lifelong learning and innovation are central. At the same time, many of today's schools still operate as they did at the beginning of the last century and are not encouraging the deep learning and skills that underlie innovative activity.

For both the individual and society, the successful management of learning is essential. Individuals who become self-directed learners are able to acquire expert knowledge in various fields, to change careers, and to endow their lives with creativity and variety. Developing these capacities is important not only for a successful economy, but also for effectively engaging in the community and society, participating in democracy, and living fulfilling and meaningful lives. Thus, society cannot risk leaving the acquisition of learning to chance.

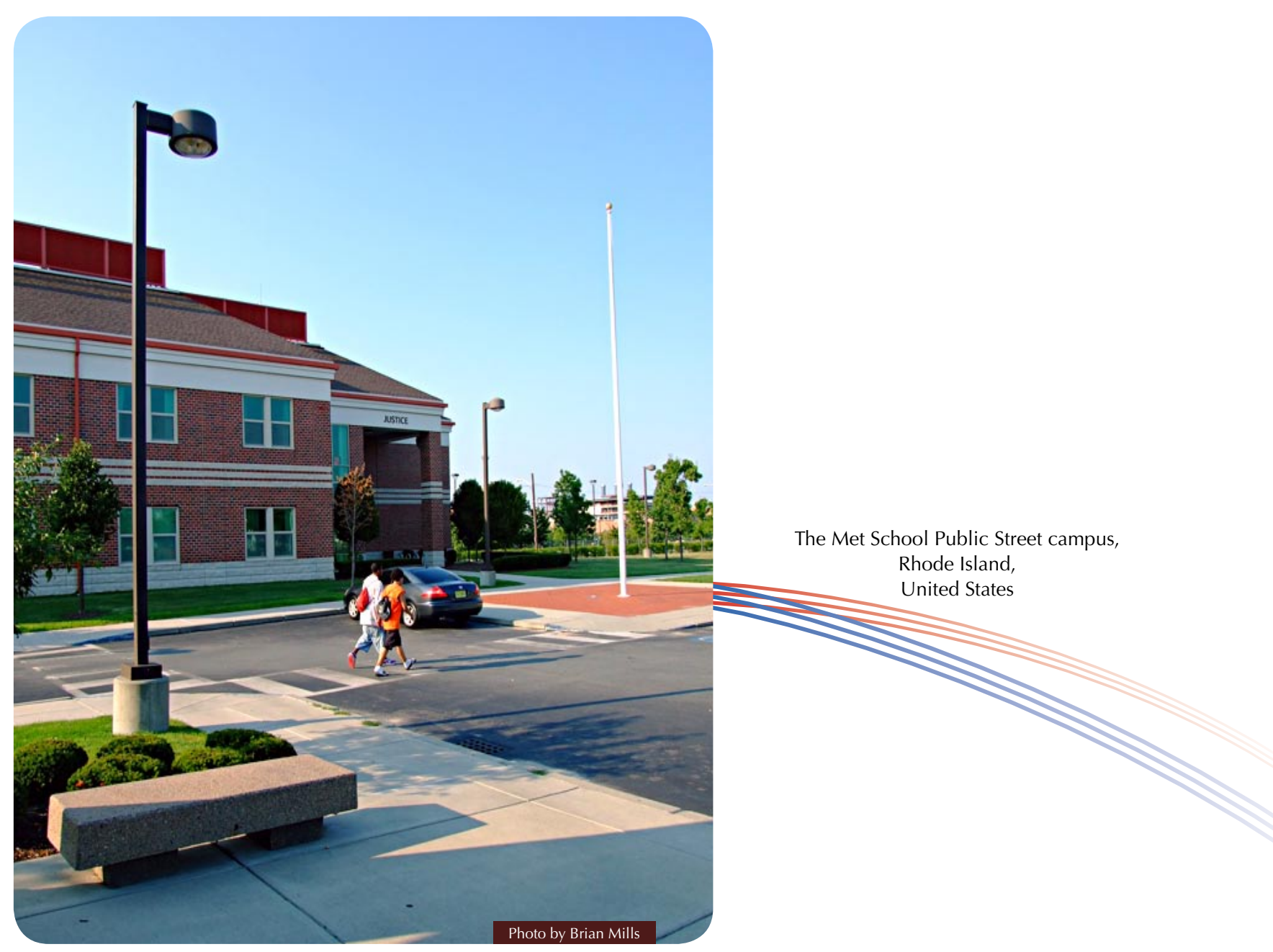




\section{LOOKING FOR INNOVATIVE LEARNING ENVIRONMENTS}

The OECD Centre for Educational Research and Innovation (CERI) launched a project in early 2008 that focuses on teaching and learning at the micro-level, rather than on educational policies, management or organisational structures. This project is based on the fundamental belief that the most fruitful area in which to search for new approaches to learning within the education system is found in the nature of learning itself.

CERI work aims to serve the educational reform agenda by generating evidence from the learning sciences and providing innovative examples from the field which invite questions about transforming teaching and learning practices in today's schools.

The specific aims of the project are to:

- analyse and synthesise current international research findings on learning, teaching and learning environments;

- identify and analyse examples of innovative learning environments from all over the world;

- engage with the community of policy reformers, innovators and learning scientists in discussions on how to better use these findings to make OECD education systems learning-driven.

\section{WHAT WE KNOW ABOUT LEARNING? LOOKING AT RESEARCH}

The common image of a teacher standing in front of a class, providing information to students sitting passively at their desks is simply archaic, according to contemporary scientific views of the learning process. But what exactly do we know? While traditional education has emphasised memorisation and the mastery of text, research on learning has shown that people construct new knowledge and understandings based on what they already know and believe. The importance of allowing students to take control of their own learning and, thereby, become active learners who are able to understand complex subject matter is another major finding of the learning sciences. This can be achieved by taking into account meta-cognitive as well as motivational and affective factors in learning. In general, learning must be seen as a social, cultural, intrapersonal and, most of all, active process.

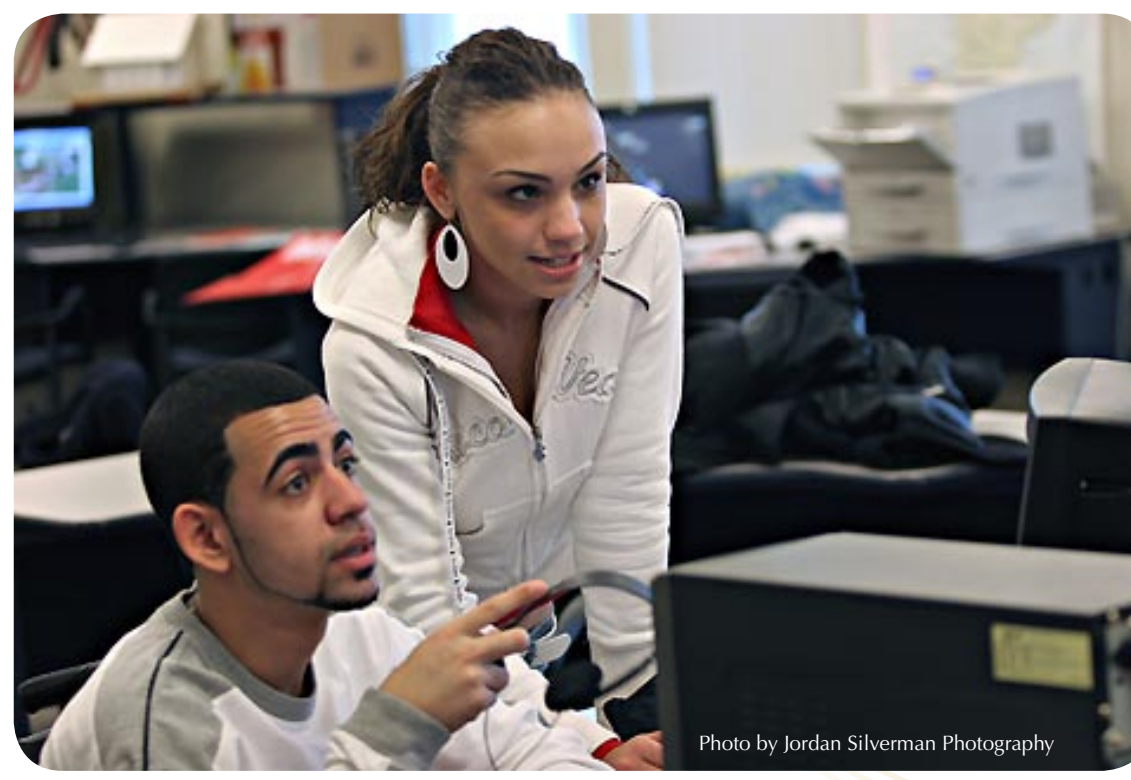




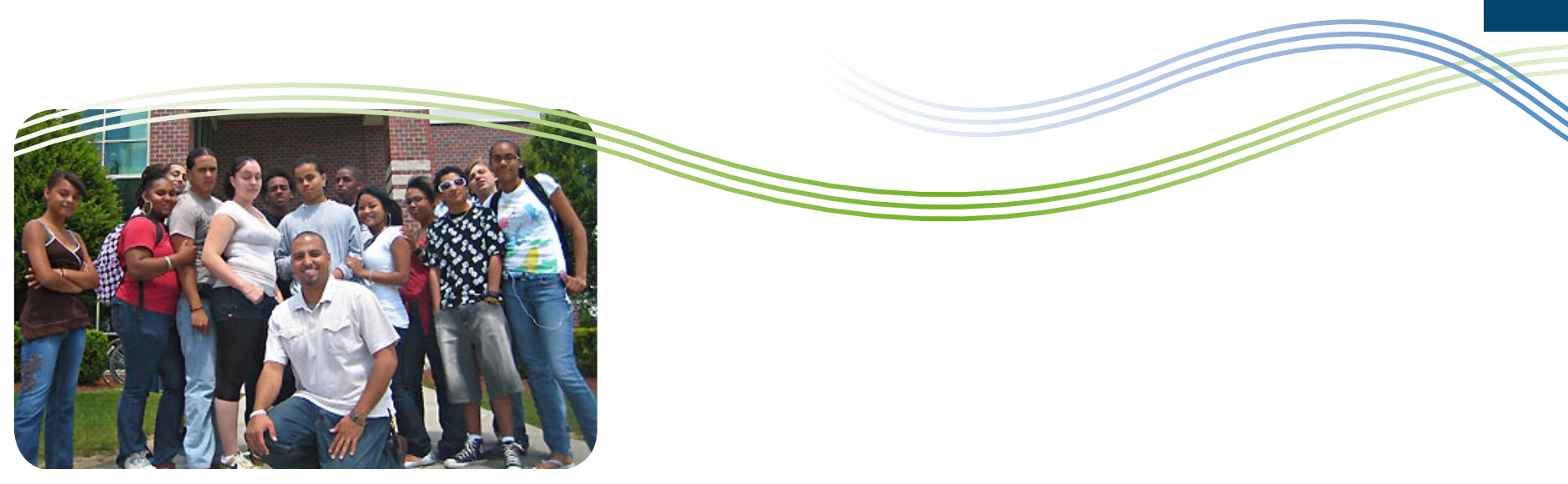

While there is no universal best teaching practice, general principles of teaching and learning - that can enhance our understanding of the teaching-learning process - unquestionably exist. The goal of the analytical strand of the CERI project is to provide evidence on the cognitive, affective, social, motivational and developmental factors that constitute the learning process. These key research findings will be synthesised in order to use this knowledge to redesign classrooms and other learning environments so that students learn more deeply and effectively. A research-based report on learning principles is expected by mid 2009.

\section{HOW DOES LEARNING WORK IN PRACTICE? LOOKING AT THE FIELD}

When looking at the field, a great deal of innovative educational initiatives can be found all around the world. The learning sciences provide support for core features of many of these innovative learning environments: their instructional methodology concentrating on experience and reflection, their integrated curriculum, and their focus on independent and customised learning combined with formative assessment. There is sound evidence showing that a deep conceptual understanding of complex concepts is best achieved in settings that involve learners and other people from the community in activities where knowledge is being applied. In this regard, those innovative learning environments that already exist in the field are ahead of mainstream education and can serve as meaningful examples for the renewal of learning environments in schools around the globe.

The empirical strand of the project will identify concrete exemplars of the innovative learning environments that already exist in OECD countries. CERI will compile a set of case studies and analyse a subset of them.

\section{EXAMPLES OF INNOVATIVE LEARNING ENVIRONMENTS}

During the development of the project proposal, as well as during its "exploratory phase" (2006-07), several innovative learning environments were identified in all OECD countries and in some non-member countries. Many of them are highly innovative learning communities and are found in both urban and rural areas. Some are specialised schools (technology, sports, arts), while others are community centres that appear to achieve better results than traditional schooling.

Box 1 presents one such innovative learning environment, which can be contrasted with traditional forms of schooling. It may not be the most prototypical case, nor will it necessarily be included in the list to be generated by the project. However, it illustrates what innovative learning environments can look like in practice and what will be the focus of the empirical strand. 


\section{Box 1 The Met: an innovative learning environment}

The Metropolitan Regional Career and Technical Center (The Met), a Big Picture School, is a network of six small high schools across three campuses in Rhode Island, United States. The Met's student population of 690 is ethnically diverse, and $65 \%$ of the students are from low-income families.

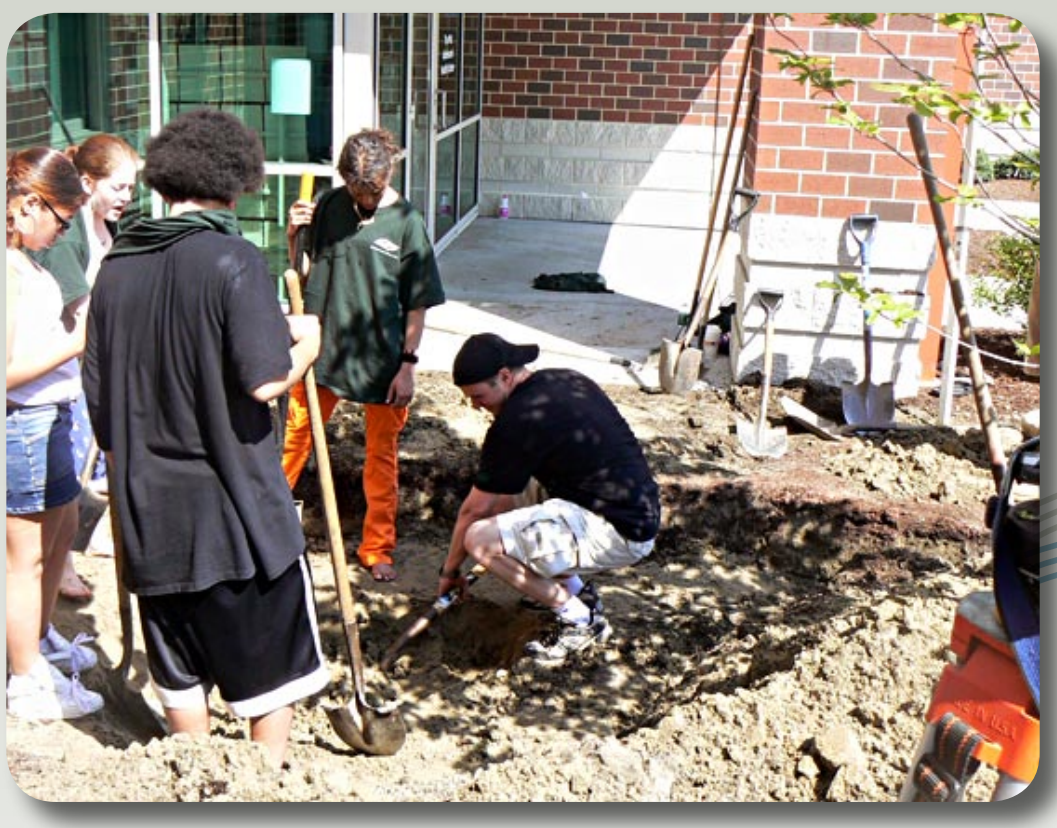

Students preparing the area for The Met's "Dynamic Theatre" statue in front of the Media and Arts Centre at the Public Street campus

The Met's mission is to develop graduates that are active and responsible citizens, productive skilled workers, and lifelong learners. The Met provides a personalised learning environment that allows students to take control of their learning and gain the skills and knowledge necessary to achieve success beyond high school. It aims to teach students empirical reasoning, quantitative reasoning, communication, social reasoning and personal qualities. The Met addresses the whole learner, including the student's physical, mental and emotional well-being. Students are organised into advisories: groups of 15 individuals in the same grade level and led by an advisor, who stays with them for all four years of upper secondary school. Students are also paired with adult mentors who share their career interests; this is because school-based learning is blended with outside experiences through an internship programme. Students develop their own challenging and personalised learning plans every quarter with the help of their advisors and parents. Instead of multiple choice tests and exams, students defend their work each quarter in exhibitions before advisors, parents, mentors and peers. Instead of grades, students receive quarterly narratives, in which the advisor describes the student's academic and personal growth in detail. There are no standard fixed-time classes. 
The Met is not just a school but also a community centre where community members participate in the school's daily workings. The Met Public Street campus on the South Side of Providence includes an adolescent health centre, fitness centre, and media and arts centre.

The school has proven successful: on average, $98 \%$ of the graduates are accepted to university, the graduation rate is $94 \%$ (the city's average is $54 \%$ ) and the attendance rate is $92.1 \%$ (the city's average is $80 \%$ ). According to the Rhode Island's School Accountability for Learning and Teaching Surveys, the Met has consistently ranked among the state's top high schools for parent involvement, school climate and quality of instruction.

The Met is a state funded, local education agency, which reports directly to the Rhode Island State Board of Regents and Department of Education and The Met School Board of Trustees. The Met was founded in 1996 by Dennis Littky, Elliot Washor and The Big Picture Company (www.bigpicture.org). Big Picture Company/Big Picture Learning, is a non-profit organisation whose mission is to lead vital change in education policy at the state, national and international levels by creating and sustaining innovative schools based on studentcentred learning.

Based on the design of The Met, in Providence, Rhode Island, there is now a national network of more than 54 Big Picture Schools and others located internationally in Australia, Israel and The Netherlands.

For more information, visit www.oecd.org/edu/learningenvironments or contact:

Francisco Benavides

OECD Centre for Educational Research and Innovation

2, rue André-Pascal

75775 Paris Cedex 16

France

E-mail: francisco.benavides@oecd.org 


\section{ORGANISATION FOR ECONOMIC CO-OPERATION AND DEVELOPMENT}

The OECD is a unique forum where the governments of 30 democracies work together to address the economic, social and environmental challenges of globalisation. The OECD is also at the forefront of efforts to understand and to help governments respond to new developments and concerns, such as corporate governance, the information economy and the challenges of an ageing population. The Organisation provides a setting where governments can compare policy experiences, seek answers to common problems, identify good practice and work to co-ordinate domestic and international policies.

The OECD member countries are: Australia, Austria, Belgium, Canada, the Czech Republic, Denmark, Finland, France, Germany, Greece, Hungary, Iceland, Ireland, Italy, Japan, Korea, Luxembourg, Mexico, the Netherlands, New Zealand, Norway, Poland, Portugal, the Slovak Republic, Spain, Sweden, Switzerland, Turkey, the United Kingdom and the United States. The Commission of the European Communities takes part in the work of the OECD.

OECD Publishing disseminates widely the results of the Organisation's statistics gathering and research on economic, social and environmental issues, as well as the conventions, guidelines and standards agreed by its members.

This work is published on the responsibility of the Secretary-General of the OECD. The opinions expressed and arguments employed herein do not necessarily reflect the official views of the Organisation or of the governments of its member countries. 